\title{
Use of IT technologies in the management of production process quality
}

\author{
Elżbieta Milewska ${ }^{1, *}$, and Bartłomiej Skowron ${ }^{2}$ \\ ${ }^{1}$ Silesian University of Technology, Faculty of Organization and Management, Institute of Production \\ Engineering, ul. Roosevelta 26, 41-800 Zabrze, Poland \\ ${ }^{2}$ UIBS Teamwork Sp. z o.o., ul. Por. K. Ogrodowskiego 27, 44-203 Rybnik, Poland
}

\begin{abstract}
When presenting the functionality of IPOsystem ${ }^{\mathrm{TM}}$, the author of the article described the manner of controlling the quality of products and calculating the technical cost of production in a selected production plant. In the article actions taken to remove product quality nonconformities have been discussed and a calculation by the subtractive factor method has been presented. Limitations of the described IT tools have also been illustrated with an example of implementation.
\end{abstract}

\section{Introduction}

Continuous improvement of the quality of products, services and production processes results from the consumer market requirements and prevailing trends. An important issue is the way of implementing and observing quality management standards in a company. A Quality Management Standard compliant with ISO 9001:2015 standard [1] is applied in all branches and institutions of various kinds and sizes. The process approach used when developing and improving the quality management system not only streamlines the circulation of information and documents in an institution, but it also brings in a precise division of tasks, competences and responsibilities of the employees [2] (Fig. 1). The organization achieves the result of effective business activity, enabling it to increase customer satisfaction, adjust to the changing conditions on the market and maintain the market position.

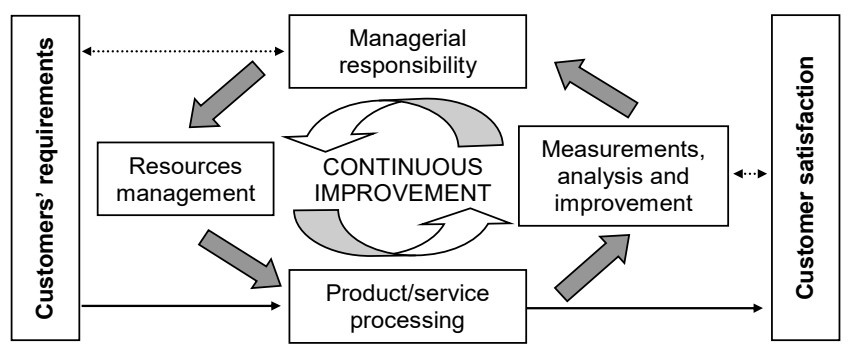

Fig. 1. Dynamic structure of a quality management system according to ISO 9001:2008 standard

\footnotetext{
${ }^{*}$ Corresponding author: elzbieta.milewska@polsl.pl
} 


\section{Product quality improvement}

Manufacturing process control is an important aspect of enterprise activity [3-9]. Based on numerous studies regarding production costs analysis, one can conclude that failure to meet quality requirements is frequently a source of additional costs, causing unexpected financial losses for the enterprise $[10,11]$.

Actions that eliminate the identified nonconformities, but, at the same time, generate additional costs, include [12]:

- correction of errors, involving the necessity to use additional materials, raw materials or utilities, as well as the use of different tools, etc.;

- performing additional technological operations which restore the initial quality of a product;

- conducting another quality control;

- performing diagnostic tests to establish the source of nonconformities;

- utilization of damaged products which cannot be repaired or reused.

Popularization of quality management systems caused that contemporary enterprises base their activities on the functioning of IT systems $[13,14]$. The reasons and effects of product nonconformities are defined and errors in the course of the production process are identified using production management support systems. Application of IT systems provides tangible benefits, which contribute to reduced costs of product manufacturing [15]. Following changes in the value of components of the technical production cost structure enables evaluating a defective product, taking into account both the time of the defect occurrence and the duration of its forming. This evaluation should include both the cost of direct production materials and direct wages. They are calculated on the basis of the number of man-hours devoted to the performance of technological operations involved in the order until a nonconformity is found. Particular attention in the calculation of a technical production cost should be paid to estimating the activities involved in the restoration of the initially planned quality of a manufactured element [16], utilization of defective products as well as diagnostics enabling identification of the cause or/and source of nonconformity. The above described analysis makes it possible to implement corrective or preventive actions, which allow reducing the identified problem [17].

In the context of the above considerations, an important issue is specifying the production process check points. They are an intermediate stage of the product manufacturing process, in which its technological parameters should be controlled or the conformity of halfproduct quality should be verified. For the final product check is an obvious procedure. Production process monitoring provides a basis for decisions controlling the flow of materials in a company. The most commonly applied measure of production process disturbances is the product quality level indicator. It represents a ratio of the number of defects to the total number of manufactured units, or to the number of checked products [1, 18-20]. Deviations between the expected and obtained value can be eliminated by changing the operation technological parameters, changing the material structure of the order or changing the workstation instructtions. Another variant of actions regulating the flow and aiming to offset the expected and obtained value is quantitative correction of the adopted standards. Correcting the conditions of the production process is the most radical action aimed at changing the algorithm of operational production plannning [13].

\section{Example of implementation supporting quality management}

The subject of investigations was a Polish producer of highly specialist tailor-made machines. The enterprise has implemented a system to support production management called IPOsystem $^{\mathrm{TM}}$. 
IPOsystem $^{\mathrm{TM}}$ is a product of UiBS Teamwork Sp. z o.o., based on Microsoft SQL Server platform. The system functionality includes planning, controlling and recording of manufacturing activities. Planning takes into account the working time and the adjustment of resources to the processing of tasks, material availability as well as limitations in the performance of works in the form of retooling, brigade work and others. Tasks are allocated autonomously. Instructions for performing some work are given using a terminal, which is placed in the hall and connected to the server. The terminal, working in a Unique $125 \mathrm{kHz}$ system, identifies the contractor by an RFID proximity card. It gives orders to do some work and receives reports from an employee in an alternate way, which is a solution providing systematic information on the course of manufacturing works. Apart from current recording of the time of commencing and finishing technological operations, IPOsystem ${ }^{\mathrm{TM}}$ allows for a possibility of recording the number of half-products leaving the workstation as well as the number of rejects, for which the previously adopted classification of nonconformity causes is applied.

Moreover, the functionality of IPOsystem ${ }^{\mathrm{TM}}$ supports users in activities related to auditing the quality of materials, half-products and final products, thus enabling them to check compliance of the obtained evaluation with the requirements contained in constructional or technological documentation. Control is determined by prior declaring an order for acontrol operation - either a workstation or walk-around one - in the production technology, and granting relevant system permission to the controller. Workstation control takes place at a controller's measuring station, whereas walk-around control is performed at a workstation of a direct production employee as a response to call.

The controller is a user of IPOsystem ${ }^{\mathrm{TM}}$, who, using the functions of Quality Control window, downloads tasks, records the result of control and, in justified cases, stops his activities. The tasks are sequenced in the window according to their urgency, with a division into workplace control and walk-round inspection.

IPOsystem $^{\mathrm{TM}}$ allows for simultaneous performance of a few control works and continuing the operation by another controller. Noting a positive outcome of the control results in giving an instruction to perform another operation, whereas a negative outcome immediately stops the production order. The order can be resumed after modifying the technology, as the default setting of the system is attempting to repair the defects. For this purpose, the order can be supplemented with additional repair operations, restoring the required quality of products as well as with an operation of conducting another quality check. The recording of unrepairable defects in IPOsystem ${ }^{\mathrm{TM}}$ results in an autonomic reduction of the number of products in the order. In the event there are a few major products in the order, the number of recorded defects indicates the number of defective sets. Evaluation of actions involved in the elimination of identified nonconformities complies with the adopted manner of production costs calculating. It has application in conjugated production (also known as combined or correlated), as a result of which three types of products are produced simultaneously from one raw material:

- a main product whose production is the primary purpose of the company's operation;

- by-product, created accidentally, having a certain utility value, that can be sold or used for own needs;

- production waste - a worthless product requiring disposal or repair.

Calculation of production costs in IPOsystem ${ }^{\mathrm{TM}}$ is conducted on an object, that is the production order. Acceptance of products from production is carried out in accordance with the proportion reflecting the mutual quantitative correlation between main products in the order. The employee's report may additionally include reporting an identified nonconformmity. This causes an automatic evaluation of the product, which takes into account both the cost of materials used and direct wages, calculated on the basis of recorded hours worked by contractors. In the event corrective actions are taken, the technical cost of production is 
increased by the cost of operations which restore the initially planned quality of the product.

Improvement of the production process requires prior identification of defects and the causes of nonconformities. As IPOsystem ${ }^{\mathrm{TM}}$ forces continuous monitoring of events, which shows the occurrence of disturbances in the production process and corrective actions undertaken to remove a quality nonconformity, the technology diagrams are corrected on an ongoing basis. The updated technology is used in new orders. Improvement of production processses is also supported by advanced analytical tools of IPOsystem ${ }^{\mathrm{TM}}$. The scope of data collected in the data system enables the deviations from the plans and production costs to be analysed. It is also possible to conduct a comparative analysis of processes of various production orders which have an identical final effect but are started at different times. The obtained results are used to specify the most favourable conditions for running a business.

\section{Conclusion}

A measure of effective functioning of a production enterprise is an efficient flow of information integrated with a qualitative and quantitative stream of material flow. A solution increasing the flexibility of actions is implementation of IT systems to support production activity. Striving to achieve a product quality compliance with the customers' requirements is determined not only by the management support, but also by the awareness of employees with regard to eliminating the causes of production process disturbances. It is a basis for improvement of the company processes.

This article was created as part of statutory work 13/030/BK_18/0039 conducted at the Institute of Production Engineering at the Faculty of Organisation and Management of the Silesian University of Technology.

\section{References}

1. EN ISO 9001:2015 Quality management systems - Requirements

2. B. Berret-Koehler, J. Kenneth, A. Kiser, M. Sashkin, Putting Total Quality Management to Work (Wiley \& Sons, 1993)

3. M. Assid, A. Gharbi, A. Hajji, Int. J. Adv. Manuf. Technol., 72 (2014)

4. S.M. Sajadi, M.M. Seyed Esfahani, K. Sörensen, Int J Adv Manuf Technol 53, (2011)

5. M. Caramanis, A. Sharifnia, Int. J. Flex. Manuf .Syst., 3 (1991)

6. R. Akella, P.R. Kumar, Optimal control of production rate in a failure prone manufacturing system. IEEE Trans. Autom. Control., 31, 116-126 (1986)

7. K. Dhouib, A. Gharbi, M.N. Ben Aziza, Int. J. Prod. Econ., 137, 126-136 (2012)

8. A. Gharbi, A. Hajji, K. Dhouib, Int. J. Prod. Res., 49(21), 6539-6557 (2011)

9. P. Lavoie, J.P. Kenne, A. Gharbi, IIE Trans., 4(3), 209-222 (2009)

10. R. Hlioui, A. Gharbi, A. Hajji, , Int J Adv Manuf Technol 81, 335 (2015)

11. B. Skotnicka-Zasadzien, Application of Quality Engineering Elements for the Improvement of Production Processes-Case Study, Proceedings of ICIEMS, (DEStech Publicat Inc, 2013)

12. PN- EN ISO 9000:2006 System Zarządzania Jakością - Podstawy i terminologia; (PKN, Warszawa 2006)

13. J. Kimemia, S. Gershwin, IEEE, 191 (1983) 
14. E. Milewska, Modelling a cost structure for polish manufacturer: A case study of the implementation, Conference Proceedings SGEM 2016, Book 2, Political sciences, law, finance, economics and tourism. Vol. 5, Economics and tourism. Sofia: STEF92 Technology (Sofia, 2016)

15. B. Skotnicka-Zasadzień, R. Wolniak, M. Zasadzień, Use of quality engineering tools and methods for the analysis of production processes - case study, Proceedings of the Second International Conference on Economic and Business Management. FEBM 2017October 21-23, 2017. Eds. Piman Limpaphayom, Gordon Huang, (Atlantis Press, Shanghai, 2017)

16. H. Rivera-Gomez, A. Gharbi, J.P. Kenné, Int J Adv Manuf Technol., 69, 2111-2130 (2013)

17. R. Kolman, Inżynieria jakości (PWN, Warszawa 1992)

18. A. Hamrol, W. Matura, Zarządzanie jakością. Teoria i praktyka (PWN, Warszawa 2006)

19. A. Hajji, A. Gharbi, J.P. Kenné, Int. J. Prod. Res., 42(6), 1107-1130 (2004) 